\title{
ANALISIS FAKTOR KESIAPAN PERAWAT DALAM PRAKTIK KOLABORASI INTERPROFESIONAL DI RUMAH SAKIT PANTI NUGROHO YOGYAKARTA
}

\section{FACTORS OF NURSE READINESS FOR INTERPROFESSIONAL COLLABORATION PRACTICE (ICP) IN PANTI NUGROHO HOSPITAL, YOGYAKARTA}

\author{
Chatarina Setya Widyastuti ${ }^{*}$ \\ *1Program Studi Profesi Ners Stikes Panti Rapih, Yogyakarta, Jalan Tantular 401 Condongcatur, \\ Depok, Sleman, Email: chatarinasw@stikespantirapih.ac.id, Indonesia.
}

\begin{abstract}
Background: The best service in the patient cannot be separated from the collaboration practice among the professional health personal in providing the integrated service to the patient, including nurses. The ability to explain the knowledge, skills and role of nurses to other health professionals well is a competency that must be mastered by nurses as one of the members of an interprofessional team.

Objective: find out the factors that influence nurse readiness in interprofessional collaboration practice (ICP) Methods: This study uses cross sectional design with total population of 63 nurses in hospital. Instrumen of this research used a valid and reliable quesioner. All data in this study analyzed univariate, bivariate and multivariate.

Results: External and internal factors influence the readiness of interprofessional collaboration practice with $\mathrm{p}$ value 0.000 . The most positive relationship is on social and interpersonal factors of consideration (correlation $0.739^{* *}$ ). Ability variables age, education, social and interpersonal considerations, physical, organizational and institutional environments, behavior, intrapersonal and intellectual in explaining the variance of variables of readiness of interprofessional collaboration practice is $35 \%$.

Conclusion: Overall, the most factors that influence nurse readiness of interprofessional collaboration practice is social and interpersonal consideration (correlation $0.739^{\star *}$ )
\end{abstract}

Keywords: Nurse Readiness, Interprofessional Collaboration Practice, factors analysis

\section{PENDAHULUAN}

Dalam dunia kesehatan, praktik kolaborasi sangatlah penting. Permasalahan pasien yang kompleks tidak dapat ditangani hanya oleh satu profesi medis, melainkan harus melibatkan berbagai profesi. Praktik kolaborasi bukan hanya diperlukan demi keselamatan pasien, tetapi juga untuk meningkatkan kepuasan serta terciptanya mutu pelayanan kesehatan yang baik. Pelayanan terbaik pada pasien tidak akan lepas dari praktik kolaborasi antar tenaga kesehatan profesional dalam memberikan pelayanan secara terintegrasi kepada pasien,
Berdasarkan data dari WHO, 70-80\% kesalahan dalam pelayanan kesehatan disebabkan oleh buruknya komunikasi dan pemahaman di dalam tim. Kerja sama tim yang baik dapat membantu mengurangi masalah patient safety. Dalam penelitian yang dilakukan pada pasien geriatri yang diberikan pelatihan oleh tim interprofesional menunjukkan bahwa praktik berbasis masyarakat dapat berhasil mendukung pelatihan tim interprofesional dan bahwa pelatihan tersebut dapat mengarah pada proses dan hasil perawatan yang lebih baik untuk pasien dewasa. ${ }^{1}$ salah satunya adalah oleh perawat. 
Semua profesional, termasuk perawat harus berubah dari service oriented menjadi pendekatan patient-centred collaborative dalam perawatan. Perubahan nilai dari service oriented menjadi pendekatan patientcentred collaborative ini dibutuhkan dalam organisasi kesehatan untuk melaksanakan kolaborasi interprofesional dalam praktik yang berpusat pada pasien. ${ }^{2}$ Literatur lain juga menunjukkan bahwa kerjasama meningkatkan kualitas dan efektifitas biaya pelayanan. $^{3}$

The Institute of Medicine (IOM) telah memberikan banyak bukti tentang dampak positif yang dapat dimiliki oleh kolaborasi lintas disiplin dan kerja tim pada dimensi kunci dari kinerja organisasi (IOM, 2000, 2001, 2003, 2010). Namun, kemampuan untuk berkolaborasi secara konsisten, dan dengan cara yang menjamin perawatan berkualitas, terus kita hindari. Kurangnya kolaborasi interdisipliner ini tetap menjadi tantangan penting bagi para eksekutif perawatan kesehatan, dekan kampus, perawat praktik, dokter, dan profesional perawatan kesehatan lainnya. ${ }^{4}$

Kendala komunikasi antarprofesi kesehatan seringkali memicu terjadinya kesalahan penangan kepada pasien yang dapat merugikan pasien. Barier komunikasi interprofesional antara lain adalah perilaku sering merendahkan profesi lain, terlalu berharap pada profesi lain, kurang memahami kompetensi dan peran dari profesi lain, tidak pernah dididik bersama profesi lain dan stereotyping. Di samping itu, pemicu lain adalah dimungkinkan karena kesiapan profesi kesehatan dalam melakukan kolaborasi interprofesional itu sendiri. Kerja interprofesional yang lebih baik dan kerja sama antara profesional kesehatan akan meningkatkan hasil perawatan pada pasien, hirarki institutional dapat menghambat komunikasi, yang dapat berpengaruh negatif terhadap perawatan pasien.

Sebuah artikel yang berjudul "articulating nursing in an interprofessional world" menyatakan bahwa kemampuan menjelaskan pengetahuan, keterampilan dan peran perawat kepada profesional kesehatan yang lain dengan baik adalah kompetensi yang harus dimiliki perawat sebagai salah satu anggota tim interprofesional. Perawat, koordinator perawat, dan dosen perawat ditantang untuk terlibat dalam praktik interprofesional sehingga mampu mempengaruhi perkembangan pendidikan tenaga kesehatan dan lingkungan praktik. ${ }^{5}$

Perawat dapat menjadi anggota tim kolaboratif melalui: (1) re-sosialisasi; (2) pemahaman dan penyampaian peran perawat, pengetahuan dan ketrampilan untuk yang lain; (3) sharing hal yang sama dengan perawat dari pelayanan kesehatan lain; (4) mengidentifikasi di mana peran dapat dibagi, pengetahuan dan keterampilan yang baik; dan (5) belajar bekerja dalam tim kolaborasi. ${ }^{2}$ Hasil penelitian menunjukkan bahwa $46 \%$ praktik kolaborasi dokter perawat dipengaruhi 
oleh karakteristik perawat yang meliputi usia, pendidikan, posisi fungsional, dan lama bekerja. Sedangkan karakteristik dokter (usia, pendidikan, dan lama bekerja) memberikan pengaruhi sebesar 43,5\%. Hal ini menunjukkan bahwa banyak faktor yang mempengaruhi praktik kolaboratif interprofesional yang perlu diteliti lebih jauh. ${ }^{6}$

Rumusan masalah dalam penelitian ini adalah apakah faktor yang berhubungan dengan kesiapan perawat dalam praktik kolaboratif interprofesional di Rumah Sakit Panti Nugroho, Yogyakarta.Tujuan penelitian ini adalah mengetahui faktor yang berhubungan dengan tingkat kesiapan perawat dalam praktik kolaborasi interprofesional di Rumah Sakit Panti Nugroho Yogyakarta.

\section{BAHAN DAN CARA PE NE LITIAN}

Jenis penelitian ini adalah deskriptif kuantitatif. Penelitian ini menggunakan design cross sectional untuk melihat gambaran tentang berbagai faktor yang behubungan dan mempengaruh kesiapan perawat dalam melaksanakan praktik kolaboratif interprofesional.

Populasi pada penelitian ini adalah semua perawat di ruangan rawat jalan dan rawat inap Rumah Sakit Panti Nugroho, Yogyakarta. Teknik pengambilan sampel dilakukan dengan cara total populasi. Perawat yang bertugas di ruang rawat inap rumah sakit adalah sejumlah 63 orang. Kriteria responden pada penelitian ini adalah: perawat yang terdata bertugas di ruang rawat jalan dan rawat inap rumah sakit dan bersedia menjadi responden dengan menandatangani informed consent.

Pengumpulan data dilakukan dengan menggunakan kuesioner kesiapan praktik interprofesional yang diambil dari modifikasi kuesioner RIPLS yang validitas dan reliabilitasnya sudah dinyatakan baik. Hasil penelitian menyatakan bahwa kuesioner RIPLS sudah divalidasi untuk digunakan pada kontek setelah lulus, dan dapat digunakan peneliti untuk melakukan pengkajian kepada sikap tenaga kesehatan profesional pada level praktik interprofesional, kerja sama praktik komunitas atau pendidikan dan pelatikan tingkat nasional. ${ }^{7}$ Hasil analisis reliabilitas dan validitas kuesioner yang dikembangkan oleh peneliti di RS swasta lain menunjukan bahwa kuesioner reliable, dengan nilai Alpha cronbach 0,855 (>0.6).

Analisis data univariat digunakan untuk menyajikan data terkait karakteristik responden dan data tentang kesiapan perawat dalam praktik kolaboratif. Analisis bivariat digunakan untuk mengetahui bagaimana hubungan antara karakteristik responden, faktor pertimbangan sosial dan interpersonal, faktor lingkungan fisik (physical environment), faktor organisasional dan institusional (organizational and institutional factor), faktor perilaku, faktor intrapersonal dan faktor intelektual dengan tingkat kesiapan praktik interprofesional. Data 
variabel yang dianalisa adalah data numerik yang terdistribusi normal sehingga uji parametrik digunakan adalah uji korelasi Pearson. ${ }^{8}$ Analisis multivariat dilakukan menggunakan regresi linier bergada karena data variabel dependen adalah numerik dan terdistribusi normal.

\section{HASIL DAN PEMBAHASAN}

Tabel 1. Karakteristik Responden $(n=63)$

\begin{tabular}{lcc}
\hline Karakteristik & $\mathrm{n}$ & $\%$ \\
\hline J enis Kelamin & & \\
\hline Laki laki & 11 & 18 \\
\hline Perempuan & 51 & 82 \\
\hline Jumlah & 63 & 100 \\
\hline Tingkat Pendidikan & & 11 \\
\hline SPK & 7 & 89 \\
\hline D III & 56 & 100 \\
\hline Jumlah & 63 & \\
\hline Tempat Dinas & & 46 \\
\hline Rawat Jalan & 29 & 54 \\
\hline Rawat Inap & 34 & 100 \\
\hline Jumlah & 63 &
\end{tabular}

Sumber: Data Primer 2016

Hasil penelitian menunjukkan bahwa sebagian besar responden berjenis kelamin perempuan, yaitu sebanyak 51 (82\%), sebagian besar responden berada pada tingkat pendidikan DIII, yaitu sebanyak 56 (89\%), lebih dari separo responden bekerja di unit rawat inap, yaitu sejumlah 34 (54\%).

Hal ini sesuai dengan data nasional yang menyatakan bahwa perawat di Indonesia didominasi oleh jenis kelamin perempuan. Sejarah telah menyatakan, profesi keperawatan diawali oleh seorang wanita yaitu Florence Nightlingale yang kemudian mengajak beberapa wanita untuk bergabung bersamanya dalam merawat pasien. Tokoh keperawatan ini pada awalnya membawa fungsi nurturing yang secara sosial dibebankan kepada perempuan. Seiring dengan perkembangan jaman, profesi perawat mulai diminati oleh kaum laki-laki karena peran yang harus diperankan sebagai perawat dapat dijalankan dan berbagai tempat kerja secara spesifik membutuhkan perawat laki-laki. Di samping itu profesi perawat merupakan profesi yang mampu bersaing dengan profesi tenaga kesehatan lainnya.

Tuntutan PPNI (Perawat Nasional Indonesia) untuk meningkatkan tingkat pendidikan perawat menjadi minimal pada tingkat sarjana (S1) tidaklah mudah. Sesuai dengan data dalam penelitian ini, masih banyak rumah sakit terlebih $\mathrm{RS}$ tipe $\mathrm{B}$ seperti lokasi dalam penelitian ini, yang perawatnya berada pada jenjang DIII karena alasan kemampuan rumah sakit. Proses peningkatan jenjang pendidikan perawat ke jenjang S1 sudah dilakukan tetapi proses tersebut berjalan lambat karena berbagai faktor termasuk kemampuan finansial rumah sakit.

Hasil penelitian menunjukkan lebih dari separuh responden bekerja di unit rawat inap, yaitu sejumlah 34 (54\%). Data ini menunjukkan bahwa perawat di Rumah Sakit Panti Nugroho yang merupakan rumah sakit tipe $B$ dengan kapasitas 50 tempat tidur lebih banyak berada di unit rawat inap. Praktik kolaborasi interprofesional secara komprehensif lebih sering dan lebih lama terjadi di unit rawat inap untuk setiap 
pasiennya karena masa perawatan yang lebih panjang dibanding di unit rawat jalan. Namun demikian praktik kolaborasi pasti dilakukan baik di unit rawat jalan maupun rawat inap.

Tabel 2. Karakteristik Usia dan Lama Kerja Responden $(n=63)$

\begin{tabular}{ccccc}
\hline Variabel & Min & Mak & Mean & SD \\
\hline Usia & 23 & 49 & 36,24 & 6,85 \\
\hline Lama Kerja & 6 & 360 & 172 & 93,1 \\
\hline
\end{tabular}

Sumber: Data Primer 2016

Hasil penelitian menunjukkan bahwa rerata usia responden adalah 36.24 tahun dengan usia terendah adalah 23 tahun dan usia tertua adalah 49 tahun. Sedangkan lama kerja terlama adalah 30 tahun, terpendek 6 bulan ( 0.5 tahun).

Data ini menunjukkan bahwa usia perawat di Rumah Sakit Panti Nugroho dapat melakukan proses estafet dengan baik karena selisih usia antara perawat yang muda dan rerata secara umum tidak terlalu jauh sehingga perawat senior sebaiknya membimbing perawat medior dan yunior dengan baik, khususnya dalam praktik kolaboratif interprofesional.

Responden dalam penelitian ini adalah seluruh perawat yang terdaftar sebagai karyawan dan bersedia menjadi responden sehingga beberapa perawat yang berstatus PKWT (Pekerja Waktu Tertentu) juga terlibat menjadi responden. Secara umum perawat di Rumah Sakit Panti Nugroho memiliki masa kerja rata rata sudah lebih dari 10 tahun. Hal ini mendukung terjadinya proses praktik kolaborasi interprofesional yang baik.
Tabel 3. Faktor yang Berhubungan Dengan

Kesiapan Perawat Dalam Praktik Kolaboratif Interprofesional $(n=63)$

\begin{tabular}{lcc}
\hline $\begin{array}{l}\text { Variabel } \\
\text { Independen }\end{array}$ & Correlations & $\begin{array}{l}\mathbf{p} \\
\text { value }\end{array}$ \\
\hline Jenis Kelamin & 0.54 & 0.675 \\
\hline Usia & $0.293^{*}$ & 0.20 \\
\hline Pendidikan & 0.165 & 0.197 \\
\hline Lama kerja & $0.252^{*}$ & 0.46 \\
\hline Tempat Dinas & -0.60 & 0.639 \\
\hline $\begin{array}{l}\text { Faktor } \\
\text { Eksternal }\end{array}$ & $\mathbf{0 . 6 6 1 * *}^{\text {** }}$ & $\mathbf{0 . 0 0 0}$ \\
\hline Faktor & &
\end{tabular}

\begin{tabular}{lll}
\hline Faktor & $0.739^{\star *}$ & 0.000
\end{tabular}

Pertimbangan

sosial dan

interpersonal

\begin{tabular}{lll}
\hline $\begin{array}{l}\text { Faktor } \\
\text { Lingkungan Fisik }\end{array}$ & $0.404^{\star *}$ & 0.001 \\
\hline Faktor & $0.370^{\star *}$ & 0.003
\end{tabular}

Organisasional

dan institusional

\begin{tabular}{lll}
\hline Faktor Intenal & $\mathbf{0 . 7 1 2}^{\text {** }}$ & $\mathbf{0 . 0 0 0}$ \\
\hline Faktor Perilaku & $0.708^{\star *}$ & 0.000 \\
\hline $\begin{array}{l}\text { Faktor } \\
\text { Intrapersonal }\end{array}$ & $0.645^{\star *}$ & 0.000 \\
\hline $\begin{array}{l}\text { Faktor } \\
\text { Intelektual }\end{array}$ & $0.566^{* *}$ & 0.000 \\
\hline
\end{tabular}

Variabel Dependen: Kesiapan praktik

kolaboratif interprofesional

** Correlation is significant at the 0.01 level (2-tailed)

* Correlation is significant at the 0.05 level (2tailed)

Sumber: Data Primer 2016

Berdasarkan hasil analisis bivariat menunjukkan bahwa terdapat hubungan yang kuat antara kesiapan praktik kolaboratif interprofesional dengan usia (correlations 0.2930 dan dengan lama kerja dengan (correlations 0.252) pada taraf signifikansi 0.05 . Hubungan yang sangat kuat juga terjadi antara praktik kolaboratif interprofesional dengan faktor eksternal (correlations 0.661) dan faktor internal (correlations 0.712) pada taraf signifikansi 0.01. Hubungan paling kuat adalah pada faktor pertimbangan sosial dan 
interpersonal (correlations 0.739). Dari hasil analisis juga menunjukkan bahwa faktor eksternal mempengaruhi kesiapan praktik kolaboratif interprofesional dengan $p$ value 0.000. Demikian pula faktor internal juga mempengaruhi kesiapan praktik kolaboratif interprofesional dengan $p$ value 0.000 . Variabel dengan $p$ value $>$ dari 0.25 pada korelasi bivariat selanjutnya tidak akan dianalisis pada analisis multivariat. Variabel yang tidak diikutkan dalam analisis multivariat regresi linier berganda adalah jenis kelamin, lama kerja dan tempat dinas.

Hasil analisis uji regresi linier berganda pada tabel ANOVA atau $F$ Test (Tabel 4) didapat nilai $\mathrm{F}$ hitung sebesar 12.24 dengan probabilitas 0.000 . Karena probabilitas jauh lebih kecil dari 0.05, maka model regresi dapat digunakan untuk memprediksi kesiapan praktik kolaboratif interprofesional atau dapat dikatakan bahwa variabel usia, pendidikan, pertimbangan sosial dan interpersonal, lingkungan fisik, organisasional dan institusional, perilaku, intrapersonal dan intelektual secara bersama-sama berpengaruh terhadap kesiapan praktik kolaboratif interprofesional.

Nilai Adjusted $\mathrm{R}$ Square adalah sebesar 0.592 maka koefisien determinasi ( $R$ Square) adalah sebesar $0.592 \times 0.592=0,35$. Berarti kemampuan variabel usia, pendidikan, prtimbangan sosial dan interpersonal, lingkungan fisik, organisasional dan institusional, perilaku, intrapersonal dan intelektual dalam menjelaskan varians dari variabel kesiapan praktik kolaboratif interprofesional adalah sebesar 35,0\%. Berarti terdapat 65\% (100\%-35\%) varians variabel kesiapan praktik kolaboratif interprofesional yang dijelaskan oleh faktor lain. Dari kedelapan variabel independen yang dimasukkan dalam model regresi, hanya ada satu variabel yaitu fator pertimbangan sosial dan interpersonal sebesar 0.001 yang signifikan pada 0.05 .
Tabel 4. Analisis Multivariat Secara Parsial
Faktor yang Berhubungan Dengan Kesiapan Perawat Dalam Praktik Kolaboratif Interprofesional $(n=63)$

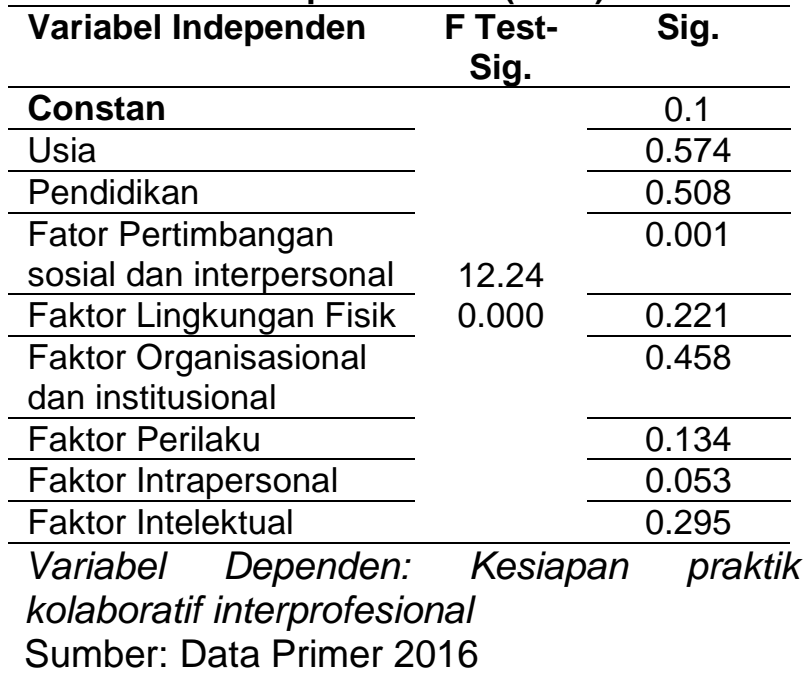

Penelitian ini menunjukkan bahwa terdapat hubungan yang kuat antara kesiapan praktik kolaboratif interprofesional dengan usia (correlations 0.293) dan dengan lama kerja dengan (correlations 0.252) pada taraf signifikansi 0.05. Sesuai dengan hasil penelitian sebelumnya yang menunjukkan bahwa $46 \%$ praktik kolaborasi dokter dan perawat dipengaruhi oleh karakteristik perawat yang meliputi usia, pendidikan, posisi fungsional dan lama bekerja ${ }^{6}$. Namun hasil penelitian ini berbeda dengan penelitian 
yang berjudul analisis pengaruh pengetahuan perawat tentang indikator kolaborasi terhadap praktek kolaborasi dokter dan perawat di unit rawat inap RSJD dr. Amino Gondohutomo Semarang yang menyatakan bahwa tidak ada hubungan antara umur, jenis kelamin dan lama kerja dengan praktik kolaborasi dokter dengan perawat. ${ }^{9}$ Berbagai kemungkinan dapat mempengaruhi hasil suatu penelitian.

terjadi antara praktik kolaboratif interprofesional dengan faktor eksternal (correlations 0.661) dan faktor internal (correlations 0.712 ) pada taraf signifikansi 0.01 . Faktor eksternal dalam penelitian ini meliputi pertimbangan sosial dan interpersonal, lingkungan fisik, organisasional dan institusional, sedangkan faktor internal dalam penelitian ini meliputi perilaku, intrapersonal dan intelektual. Hal ini sesuai dengan hasil penelitian menyatakan bahwa ada hubungan bermakna antara pengetahuan perawat dengan praktik kolaborasi. ${ }^{9}$ Salah satu faktor internal yang dianalisis adalah terkait intelektual perawat yang di dalamnya sangat erat hubungannya dengan pengetahuan perawat tentang praktik kolaborasi.

Hasil analisis bivariat penelitian ini menunjukkan bahwa faktor eksternal mempengaruhi kesiapan praktik kolaboratif interprofesional dengan $p$ value 0.000 . Faktor internal juga mempengaruhi kesiapan praktik kolaboratif interprofesional dengan $p$ value
0.000. Hasil ini menunjukkan bahwa antara faktor eksternal maupun internal dari perawat berpengaruh terhadap kesiapan praktik kolaborasi interprofesional. Sesuai penelitian yang menyatakan bahwa profesional kesehatan harus melakukan praktik sesuai area serta memahami dan mampu menunjukkan peghargaan dan berbagi kompetensi dengan tim kesehatan lainnya. ${ }^{10}$ Salah satu faktor eksternal adalah hubungan interpersonal antara perawat dengan tim kesehatan lain. Seluruh anggota tim kesehatan harus memahami peran dan keahlian masing masing, percaya diri dengan kemampuannya, mengakui adanya ikatan dalam praktik dan berkomitmen dengan nilai dan etika profesi dan mengetahui standart praktik mereka. ${ }^{10}$ Perawat yang memiliki perilaku praktik kolaboratif dan intelektual yang baik akan lebih siap dalam praktik kolaborasi dengan tenaga kesehatan lain karena dengan kompetensi yang baik maka kepercayaan dirinya menjadi tinggi.

Hasil analisis multivariat penelitian ini menunjukkan bahwa kemampuan variabel usia, pendidikan, pertimbangan sosial dan interpersonal, lingkungan fisik, organisasional dan institusional, perilaku, intrapersonal dan intelektual dalam menjelaskan varians dari variabel kesiapan praktik kolaboratif interprofesional adalah sebesar $35 \%$ sehingga ada varian lain sebesar $65 \%$ (100\%-35\%) yang dijelaskan oleh faktor lain. Variabel usia, pendidikan, pertimbangan 
sosial dan interpersonal, lingkungan fisik, organisasional dan institusional, perilaku, intrapersonal dan intelektual juga secara bersama sama berpengaruh terhadap kesiapan praktik kolaboratif interprofesional. Namun secara parsial kesiapan praktik kolaboratif interprofesional dipengaruhi oleh variabel fator eksternal 1 yaitu pertimbangan sosial dan interpersonal dengan persamaan matematis: kesiapan praktik kolaboratif interprofesional $=13.597+0.51$ usia +1.244 pendidikan +1.829 pertimbangan sosial dan interpersonal - 0.750 lingkungan fisik +0.315 organisasional dan institusional +0.735 perilaku + 0.818 intrapersonal - 0.507 intelektual. Berdasarkan persamaan ini nampak bahwa pertimbangan sosial dan interpersonal mempunyai pengaruh yang paling besar dan paling signifikan dengan $p$ value 0.001 ( $p$ <.05). Valentijn et al (2015) menyatakan bahwa efektifitas praktik kolaborasi interprofesional akan terlaksana dengan baik apabila seluruh pemangku kepentingan (profesional, manajer, pengambil kebijakan) berada pada satu garis sehingga membutuhkan pengembangan komitmen seluruh pihak dari profesional, organisasi dan sistem yang ada untuk mengintegrasikan seluruh pelayanan kepada pasien.

Hasil analisis ini sesuai dengan tulisan ilmiah yang menyatakan bahwa kemitraan tenaga kesehatan dalam kerja sama interprofesi dapat ditumbuhkan dari hasil hubungan interpersonal yang baik.
Kemitraan dapat diciptakan apabila profesi yang bermitra mampu memperlihatkan sikap saling mempercayai dan menghargai, memahami dan menerima keberadaan disiplin ilmu masing-masing, menunjukkan citra diri yang positif, masing-masing anggota profesi yang berbeda dapat menunjukkan kematangan profesional yang sama yang timbul karena pendidikan dan pengalaman, adanya keinginan dan kesadaran untuk berkomunikasi dan negosisasi dalam menjalankan tugas yang interdependen dalam pencapaian tujuan bersama. Kedua profesi memiliki kompetensi klinik dan kemampuan interpersonal, menilai dan menghargai pengetahuan yang berbeda dan saling melengkapi. ${ }^{11}$

Perawat sebagai salah satu anggota tim kesehatan dalam praktik pelayanan kepada pasien harus mampu berkomunikasi dan berinteraksi dengan tim kesehatan lain agar mampu berkontribusi dalam pelayanan holistik kepada pasien. Melalui komunikasi yang efektif, hubungan sosial dan interpersonal dengan tim kesehatan lain akan menjadi efektif sehingga outcomes terhadap asuhan keperawatan kepada pasien lebih optimal dan kepuasan pasien beserta keluarganya meningkat. Faktor hubungan interpersonal merupakan faktor yang paling besar pengaruhnya, hal ini juga sesuai dengan teori yang menyatakan bahwa domain dari praktik kolaborasi yang utama meliputi komunikasi interprofesional, Pasien klien/keluarga/perawatan, kejelasan peran, 
fungsi tim, kepemimpinan kolaboratif, resolusi konflik interprofesional. ${ }^{12}$ Demikian pula menurut The World Health Professions Alliance (WHPA) yang menyatakan bahwa praktik kolaboratif interprofesional membutuhkan kemampuan saling menghargai, kompeten, kepercayaan dan sinergis dari setiap anggota tim. Praktik kolaboratif interprofesional juga membutuhkan komunikasi yang efektif, menuntut seluruh anggota tim untuk bicara dan mendengarkan secara aktif satu sama lain. ${ }^{13}$

Perilaku membangun hubungan interpersonal dapat dibina sejak tenaga kesehatan menjalani pendidikan masa sekolah, tetapi kondisi ini belum dapat disiapkan dengan baik karena pendidikan di Indonesia belum membudayakan sistem ini secara terintegrasi terlebih dalam praktik di rumah sakit. Hal ini mengakibatkan adanya isolasi dan pandangan yang negatif antar tenaga kesehatan. Sesuai hasil penelitian yang menyatakan bahwa perilaku isolasi ini berakar kuat dalam praktik profesional bidang kesehatan yang disosialisasikan dan dididik, yaitu program yang mengisolasi mereka dari profesional layanan kesehatan lainnya, dan menghasilkan pengembangan identitas semata-mata yang tidak profesional. Identitas isolasionis ini menciptakan kurangnya pemahaman tentang, membatasi paparan, dan mendukung sikap stereotip negatif yang terus berlanjut terhadap profesional lainnya yang menghasilkan mitos dan kesalahpahaman yang berlaku mengenai peran dan kontribusi rekan profesional lainnya. ${ }^{14}$

Melalui praktik kolaboratif interprofesional, perawat akan mampu meberikan solusi yang tepat untuk permasalahan pasien dengan lebih cepat dan kepuasan pasien akan tinggi setelah memperoleh hasil yang optimal. Hal ini sesuai dengan penelitian yang menyatakan bahwa perawat di organisasi menggunakan kemitraan kolaboratif untuk menempa solusi inovatif, memperbaiki asuhan keperawatan di seluruh kontinum, memajukan kesehatan berbagai populasi, memberi efek perubahan yang diinginkan, dan memperbaiki hasil yang diharapkan. ${ }^{15}$

\section{KESIMPULAN}

Terdapat hubungan yang kuat antara kesiapan praktik kolaboratif interprofesional dengan usia (correlations 0.293) dan dengan lama kerja (correlations 0.252) pada taraf signifikansi 0.05 . Hubungan yang sangat kuat juga terjadi antara praktik kolaboratif interprofesional dengan faktor eksternal (correlations 0.661) dan faktor internal (correlations 0.712 ) pada taraf signifikansi 0.01. Faktor eksternal dan internal mempengaruhi kesiapan praktik kolaboratif interprofesional dengan $p$ value 0.000 .

Kemampuan variabel usia, pendidikan, pertimbangan sosial dan interpersonal, lingkungan fisik, organisasional dan institusional, perilaku, intrapersonal dan 
intelektual dalam menjelaskan varians dari variabel kesiapan praktik kolaboratif interprofesional adalah sebesar 35\%. Kesiapan praktik kolaboratif interprofesional dipengaruhi oleh variabel fator eksternal 1 yaitu pertimbangan sosial dan interpersonal dengan persamaan matematis: kesiapan praktik kolaboratif interprofesional $=13.597+$ 0.51 usia +1.244 pendidikan +1.829 pertimbangan sosial dan interpersonal 0.750 lingkungan fisik +0.315 organisasional dan institusional +0.735 perilaku +0.818 Intrapersonal - 0.507 intelektual

Dari hasil penelitian ini diharapkan manajemen meningkatkan fasilitasi terjadinya interaksi dan kerjasama antartenaga kesehatan di setiap praktik pemberian asuhan keperawatan karena pertimbangan sosial dan interpersonal sangat mempengaruhi dalam praktik kolaboratif interprofesional. Fasilitasi ini dapat dilakukan melalui berbagai kegiatan seperti coferensi, pembahasan kasus, refleksi kasus bersama antar tenaga kesehatan secara periodik oleh setiap perawat. Untuk peneliti selanjutnya diharapkan meneliti lebih lanjut tentang faktor lain yang mungkin berpengaruh terhadap kesiapan praktik kolaboratif interprofesional karena dari hasil penelitian ini masih terdapat $65 \%$ faktor lain yang mempengaruhi kesiapan praktik kolaboratif interprofesional.

\section{TERIMA KASIH}

1. dr. tandean Arif Wibowo, MPH, Direktur RS Panti Nugroho, Yogyakarta, email: rumahsakit.pantinugroho@gmail.com

2. dr. Agus Wijanarko, M.kes, Diremtur RS Panti rini, Yogyakarta, email: rs_pantirini@yahoo.com

\section{KEPUSTAKAAN}

1. McKenzie, G. Lasater, K. Delander, G.E. Neal, M.B. Morgove, M \& Eckstrom, E. Falls prevention education: Interprofessional training to enhance collaborative practice. Journal Gerontology \& Geriatrics Education : 2017. Volume 38, Issue 2 Pages 232-243

2. Orchard, Carole, A. Persistent isolationist or collaborator? The nurse $\mathrm{s}$ role in interprofessional collaborative practice. J ournal of Nursing Management. 2010. Volume18, 248-257

3. Interprofessional Education Collaborative. Core Competencies for Interprofessional Collaborative Practice: Report of an Expert Panel. Washington, D.C: Interprofessional Education Collaborative; 2011

4. Bankston, K., Glazer, G., "Legislative: Interprofessional Collaboration: What's Taking So Long?" OJIN: The Online J ournal of Issues in Nursing; (November 4, 2013); Vol: 19 No. 1.

5. Sommerfeldt,SC. Articulating nursing in an interprofessional world. Nurse Education Practice. 2013 Nov; 13 (6):51923.

6. Martiningsih, W. Praktek Kolaborasi Perawat-Dokter dan Faktor Yang Mempengaruhinya (Collaboration Practice between Nurses and Physician and The Factors Affecting). Media J urnal Ners. 2011. Volume : 6 - No. 2

7. Ross, R; Bruce,D; Allstaff, $\mathrm{K}$ \& McLernon, D. Validating the Readiness for Interprofessional Learning Scale (RIPLS) in the postgraduate context: are health care professionals ready for IPL? 
MEDICAL EDUCATION. 2006; 40: 415422

8. Dahlan, M.S. Statistik untuk Kedokteran dan Kesehatan. Jakarta: Penerbit Salemba Medika; 2011.

9. Rumanti, E. Analisis pengaruh pengetahuan perawat tentang Indikator kolaborasi terhadap praktek Kolaborasi perawat dokter Di unit rawat inap RSJD dr amino gondohutomo Semarang. Tesis tidak dipublikasi. 2009.

10. Nolte, Judith. Enhancing Interdisclinary Collaboration in Primary Health Care.Canada: IECP Initiative; 2005.

11. Prabandari. Interprofessional Education (IPE), Communication And Interprofessional Teamwork. Yogyakarta: FK-UGM; 2013.

12. Canadian Interprofesional Health Collaboration. A National
Interprofessional

Framework. Canada; 2010.

Competency

13. The World Health Profession Alliance (WHPA). France: Chemin du Levant .Ferney Voltaire; 2013.

14. Khalili, Hossein; Orchard, Carole; Heather K. Spence Laschinger, and Farah, Randa. An interprofessional socialization framework for developing an interprofessional identity among health professions students. J ournal Interprofesional Care. 2013. 27(6): 448453.

15. Talley, Linda B. Collaborative Partnerships: Raising the Professional Practice of Nursing. J ournal of Nursing Administration. 2016. Volume 46 - Issue 6 - p 291-292 